Prethodno priopćenje UDK 17.023.1(045)

doi: $10.21464 /$ fi 40201

Primljeno 25. 3. 2019 .

\author{
Jelena Đurić \\ Univerzitet u Beogradu, Institut za filozofiju i društvenu teoriju, Kraljice Natalije 45, RS-11000 Beograd \\ jelena.el@gmail.com
}

\title{
Ljudska priroda i kontekst napretka
}

\begin{abstract}
Sažetak
Namjera je pokazati kako značenje 'ljudske prirode' proizlazi iz pogleda na svijet kakav u kontekstu napretka modernizacije vodi obezvrjeđivanju značenja pojma ljudsko. Ukazuje se na potrebu za takvom rekonceptualizacijom ljudske prirode kakva bi povezala globalne procese $i$ onto-epistemo-etičke aspekte općeg pogleda na svijet. Ti bi aspekti predstavljali samorazumijevanje suvremene kulture. Prepreka je tom cilju aporetična struktura mišljenja, čiji se modernizacijski kontekst napretka temelji na odvajanju prirode i kulture. Odvajanjem se uspostavlja (ne)mogućnost odgovora na pitanje o tome je li kultura, kao izraz ljudske prirode, dio prirode ili je priroda, kao proizvod ljudske spoznaje, dio kulture. Umjesto nastojanja posthumanizma da tu nedoumicu riješi ukidanjem pojma ljudsko, što ne donosi rješenje ni ekološke ni drugih tipova krize, potrebno je redefinirati pojam ljudska priroda.
\end{abstract}

\section{Ključne riječi}

ljudska priroda, priroda, kultura, napredak, antropocen, posthumanizam

\section{Uvodno}

Zagonetka se ljudske prirode u doba antropocena izražava nedoumicom oko toga što pojam ljudska priroda uopće znači. Budući da se sa znanstvenotehničkom izmjenom svijeta pojam ljudske prirode mijenjao, djeluje kao da konačnog određenja nema te da svako vrijeme mora iznova tražiti svoje odgovore na izazove toga pitanja. Odgovori se mogu odnositi na pitanje »Što je čovjek? « - kako na klasičan, ali ne i zaokružen, filozofski projekt, tako i na druga načelna pitanja, poput »Odgovara li promjena razumijevanja promjeni ljudske prirode? «; »Kako shvatiti ljudsku prirodu koja se mijenja?«; »Što će nastati od ljudske prirode ako modernizacija sasvim poništi ciklično prirodno vrijeme, kao što uništava prirodu i kao što pokušava, kao iracionalan, poništiti arhetipski predio psihe?«. Suočavanje s neodlučivošću spoznaja o tim pitanjima, inherentne ljudskoj prirodi, ogleda se u rekurzivnom pitanju: »Je li kultura, kao izraz ljudske prirode, dio prirode ili je priroda, kao proizvod ljudske spoznaje, dio kulture?«

Je li taj uvid u aporetičnu strukturu krajnjeg znanja ljudsko prokletstvo? Podvojenost bića i znanja prenosi se s ljudskog spoznajnog aparata, preko jezika i pogleda na svijet, na iskustvo, a kada se pojmovnoj sferi priključi sfera tako trasiranog iskustva, uzdrmani su, čini se, postojeći kategorijalni temelji i klasifikacije koje u kontekstu moderne ideologije napretka podrazumijevaju podjele između prirode i ljudske prirode, tj. kulture. 


\section{Odvajanje prirode i ljudske prirode}

Aristotel je racionalnost, vidjevši u njoj bitnu odliku ljudskog bića, proglasio razlogom odvojenosti čovjeka od životinjskog svijeta. Po Aristotelovoj

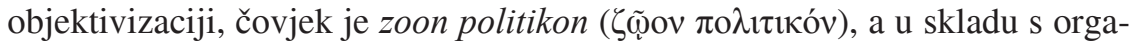
nizacijom polisa ( $\pi$ ó $\lambda$ เ $)$ i zakonima koji vladaju u njemu, uređena je i priroda. Physis ( $\varphi v ́ \sigma 1 \varsigma$ ) i nomos (vó $\mu \circ \varsigma$ ) neraskidivo su povezani, a ljudi su dio prirode zahvaljujući sposobnosti da znaju zakone koji vladaju svime. Aristotelove klasifikacije trajale su i tijekom perioda skolastike, sve do znanstvene revolucije u sedamnaestom stoljeću. Tada je znanost odbacila dvije aristotelovske vrste uzročnosti. Formalna uzročnost i svršna uzročnost prepuštene su teologiji, dok su materijalna uzročnost i djelatna uzročnost prihvaćene kao dio znanosti. ${ }^{1} \mathrm{Na}$ osnovi toga ustanovljena je ideja mehaničke prirode, čime je označeno razdvajanje prirode $\mathrm{i}$ čovječanstva. ${ }^{2}$ Tako je zavladalo uvjerenje da, iako priroda služi nekom božanskom cilju, čovjek se, kao »gospodar Stvorenog «, potpuno razlikuje od Stvarnosti koja mu je povjerena na upravljanje i koju nastoji razumjeti.

Uobičajeno se odnos ljudske dominacije nad prirodom pripisuje antropocentrizmu kršćanskog učenja, ali se pritom previđa simbolika po kojoj Stvoritelj nije ovlastio čovjeka da upravlja prirodom, 'natprirodno' ga oslobodivši odgovornosti. Održavanje božanskog reda znači čuvanje principa simetrije i sklada, dakle, razmjera između izvanjske moći i unutrašnje odgovornosti. Nasuprot tomu, mehanicistički pogled na svijet nije više obvezivao moderne filozofe takvom odgovornošću. Po modernom pogledu na svijet, priroda je postala autonomna ontološka sfera, istraživačko polje znanstvenog eksperimentiranja, predmet koji treba iskoristiti i poboljšati. Pojam prirode ostao je u sprezi s pojmom ljudske prirode koja se odvojila u funkciji opservacije mehanizma i određivanja zakona prirode. Općenitost značenja prirode i ljudske prirode omogućila je sintetiziranje novih mogućnosti. Znanje i kontrola pripali su čovjeku - znanstveniku, inženjeru, tehnologu, upravitelju - koji nije bio odgovoran za čovječanstvo pa ni za posebne kolektivitete koji su se razlikovali po običajima, jezicima i religijama. Priroda i ljudska priroda ostale su uparene antagonistički, kroz suprotstavljene dualizme u odnosima dominacije.

Moderna znanost produbila je odvojenost prirode i ljudske prirode, shvaćajući je kao činjenicu u okviru pogleda na svijet newtonovske mehanike. Ona korespondira inertnom kontekstu znanstveno-tehničkog napretka koji je oduvijek bio podređen kontroli rasta profita. Ipak, već u drugoj polovici 20. stoljeća vide se naznake da doba odvojenosti zastarijeva. Zahvaljujući znanstveno-teorijskom razvoju, objektivizirani redukcionistički i deterministički pogled na svijet počinje ustupati mjesto novim oblicima tehnike odgovarajućim novom shvaćanju materije kao nečega što je u imanentnoj vezi s duhom pripadnim sklopu prirode. Novi razvoj u fizici, evolucijskoj biologiji, ekologiji, matematici i genetici polaže znanstvene temelje za ponovno ujedinjenje duha i materije, ljudi i prirode, 'sebe' i drugih itd. Ipak, iako su na osnovi prijedloga nove znanstvene paradigme zamislivi drukčiji, održivi sistemi (ekonomije, obrazovanja, medicine, znanosti i tehnike) koji ne teže kontroli i transcendenciji prirode, već svjesnoj suradnji s njom, nije ustanovljeno jedinstveno usmjerenje $\mathrm{k}$ tome, tako da se u svim sferama ljudskih nadležnosti kriza produbljuje.

Znanost je pokazala da čovjek ne sliči samo na životinje nego da »sliči na sve jedinstvene domene, protoplazmatične i molekulske, čija nagomilanost sačinjava svemir «, ${ }^{3}$ da $»[\mathrm{k}]$ vantni svijet i makrosvijet slijede iste principe «. ${ }^{4}$ Također, prepoznata je »upletenost materije i značenja «. ${ }^{5}$ Maurice MerleauPonty kaže: 
»Nisu znanstvena otkrića dovela do promjene ideje prirode. Naprotiv, upravo je promjena ideje prirode omogućila ta otkrića. ${ }^{6}$

Također, prepoznato je da razvoj epistemološke svijesti odgovara razvoju poimanja čovjeka. Tako je Michel Foucault, prikazujući povijest epistemološke svijesti, utvrdio da prije 18. stoljeća znanost o čovjeku nije ni bila moguća i »da se u episteme klasicizma funkcije 'prirode' i 'ljudske prirode' suprotstavljaju kao oponentni pojmovi «. ${ }^{7}$ Po Foucaultovu mišljenju, upravo se kroz tu opoziciju naslućuje »pozitivni odnos « između njih, a ljudska se priroda kroz govor, »u činu imenovanja«, povezuje s prirodom. ${ }^{8}$

Možda tom pristupu, koji tvrdi da »čovjek, kao neprozirna i prvobitna realnost (...) ne zauzima nikakvo mjesto «, ${ }^{9}$ nije odgovaralo prepoznavanje arhetipskih predodžbi o čovjeku kakve su imale predmoderne kulture, zato što te kulture nisu posjedovale nikakvu objektivirajuću samosvijest. One su proizvoljno zamišljale ljudsko podrijetlo - bilo kroz mitološku preegzistenciju, bilo kroz magijsku samoniklost. Međutim, ako ovo pažljivije razmotrimo, možemo uočiti da je i ta »proizvoljnost « uokvirena suprotstavljenim opcijama, odnosno aporetičnim obrascem koji se ponavlja kroz sve aksijalne faze povijesti, kako kroz religijske, tako i kroz znanstvene dogme. Izgleda da su to zaista »dvije suprotne spekulativne politike - koje su na kraju krajeva slične podjednako su loše «10 ${ }^{10}$ jer nijedna ne nudi bolje objašnjenje čovjeka od one druge. Ipak, na osnovi tog obrasca primjećujemo jednu nit koja je izgleda in-

1

René Descartes razmatrao je samo djelatnu uzročnost, čime je Boga pretvorio u apstraktnu pokretačku silu neovisnu o inertnom mehanizmu svijeta. Francis Bacon, René Descartes i Baruch de Spinoza odbacili su intencionalnost prirode. Drukčiji pravac mišljenja, koji je bio povezan s finalitetom zakona prirode $u$ skladu sa sveukupnim planom, bio je marginaliziran - Johannes Kepler, Robert Boyle i Gottfried Leibniz imali su koncepciju prirode kao uravnotežene i jedinstvene cjeline, a njihove je ideje prihvatila teleološka orijentacija u biologiji, povezavši ih s idejom prilagođavanja organizama i homeostaze ekosistema. 2

Spinoza je bio usamljen u odbijanju tog razdvajanja, inzistirajući na tome da ljudsko ponašanje treba smatrati fenomenom kojim upravlja univerzalni determinizam (umjesto plana prirode koji je zamišljen analogno samospoznaji).

3

Ремон Рије [Raymond Ruyer], Животиња, човек, симболска функција [Životinja, с̌ovek, simbolska funkcija], preveo Živojin Živojinović, Matica srpska, Novi Sad 1966., str. 75 .

Jodi Kaufmann, »Qualitative Inquiry and the Measuring Apparatus «, u: Anne B. Reinertsen (ur.), Becoming Earth. A Post Human Turn in Educational Discourse Collapsing Naturel Culture Divides, Sense Publishers, Rotterdam, Boston, Taipei 2016., str. 15-20, str. 17.
5

»Materija i značenje nisu odvojeni elementi. Oni su nerazdvojno povezani i nema događaja, ma kako energičan bio, koji bi ih mogao odvojiti. Čak se i atomi, čije ime ó $\tau$ ouo znači »nedjeljivi«, mogu podijeliti. Ali materija i značenje ne mogu (...).« - Karen Barad, Meeting the Universe Halfway: Quantum Physics and the Entanglement of Matter and Meaning, Duke University Press, Durham 2007., str. 3.

Maurice Merleau-Ponty, La nature: Notes, cours du Collège de France, Éditions du Seuil, Pariz 1994., str. 25.

7

Mišel Fuko [Michel Foucault], Riječi $i$ stvari. Arheologija humanističkih nauka, Nolit, Beograd 1971., str. 350.

8

Dok »[o]brnuto, lanac bića vezan je za ljudsku prirodu igrom same prirode (...). Ako se ljudska priroda prepliće s prirodom, to se događa uz pomoć mehanizma znanja (...).« - Ibid., str. 351.

9

»U to vrijeme nije bilo moguće da se na ivici svijeta digne ta neobična figura bića čija bi priroda (ona koja ga određuje, drži i prožima oduvijek) bila da spoznaje prirodu i samog sebe kao prirodno biće.«-Ibid., str. 352.

10

P. Рије [R. Ruyer], Животиња, човек, симболска функиија [Životinja, čovek, simbolska funkcija], str. 9. 
herentna razumnoj strani ljudske prirode, a koja se odnosi na stalno prisustvo konceptualnih ambivalentnosti, onemogućavajući usuglašavanje suprotnih stajališta koje uparuje samo kao suprotnosti. Riječ je o aporetičnoj strukturi ljudskog mišljenja koja se očituje u različitim udvajanjima: bića i znanja/jezika/djelovanja, koja predstavlja kontekst epistemološke drame - vrela pojmovne neodređenosti i dvojnosti: pojedinačno nasuprot općeg, materijalno nasuprot duhovnog, predmeti nasuprot pojmova, objekt nasuprot subjekta, izvanjski svijet nasuprot unutrašnjeg svijeta, sebstvo nasuprot drugih itd.

»Jedini izlaz« za to, tvrdi Ruyer, jest u »živoj, nedogmatskoj znanosti «, ${ }^{11}$ znanosti koja postupno povezuje ljudski duh i poredak sa sveopćim poretkom prirode. ${ }^{12}$ Zahvaljujući tome, čovjek se ne osjeća kao tuđinac u svijetu, već se uklapa u slijed prirodnih domena i, upravo na osnovi svoje ljudske prirode, pokriva jednu posebnu domenu koja se odnosi na sposobnost »da preobraća, da 'informira' svojim radom izuzetno prostrano područje «. ${ }^{13}$

Postmoderno vrijeme, međutim, obilježeno je odbacivanjem ideje ljudske prirode, iza čega su stali mnogi suvremeni filozofi. Potrebno je rasvijetliti zašto je to tako, kada je to u suprotnosti ne samo s velikim dijelom povijesti filozofije nego i s novim znanstvenim otkrićima. To je veoma važno zbog ozbiljnosti posljedica koje takav pogled ima na samorazumijevanje ljudskog.

Kontroverza oko odbacivanja ideje ljudske prirode nastala je u kontekstu odbacivanja »esencijalizma«, odnosno uslijed sumnje u postojanje neke predodređene biti čovještva. Tijekom povijesti filozofije postojanje biti ljudske prirode uglavnom nije dovođeno u pitanje, premda je ona tumačena veoma različito. Izuzetak su bili empiristi, prije svih John Locke s idejom da se ljudsko biće rađa kao tabula rasa. ${ }^{14} \mathrm{U}$ istom su duhu i spomenuti filozofi, dolazili oni iz analitičke ili kontinentalne tradicije, odbacili ideju ljudske prirode. Nedavan primjer tog stajališta predstavlja Jesse J. Prinz, ${ }^{15}$ čiji se stavovi oslanjaju na staru raspravu o tome važniji su li utjecaji nasljeđa ili okruženja. ${ }^{16}$ Znanstvenici su otkrili da je zauzimanje jedne od ovih pozicija (nativizam $v s$. empirizam) manjkavo jer je jednostrano i da su obje strane uključene u proces razvoja (ljudske prirode) osobnosti, ističući da je interakcija između njih ključna. Dakle, postalo je jasno da nema načina da se ti faktori razdvoje, da se okruženje odnosi na ukupno iskustvo kulture i društva koji moduliraju gensko nasljeđe i vice versa.

Uzimajući u obzir znanstveni pogled na svijet, treba reći da je s Darwinom evolucijska biologija utvrdila da je grana Homo sapiensa samo jedna među milijunima drugih i da su osobine ljudske vrste rezultat procesa evolutivne diferencijacije primata. S obzirom na to da evolucijski kontinuitet traje, nema nepromjenjivih crta, odnosno nekakve »biti« koja bi striktno utvrdila razlike između ljudskog i životinjskog carstva. Znanstvena činjenica da se ljudi razlikuju od čimpanza sa samo 1-2\% genskih sekvenci obično se navodi kao primjer toga da čovjek nije bitno različit. Međutim, na osnovi nedavnih znanstvenih otkrića ${ }^{17}$ zna se da se taj mali postotak zatim translatira u tisuce strukturnih promjena na genskom planu koje se onda kombiniraju, stvarajući milijune načina koji razlikuju ljudsku vrstu. To što je genska razlika procentualno mala ne znači da nije očigledna i da nema značajne posljedice. Po tome, evolutivna i razvojna biologija podržavaju postojanje ideje ljudske prirode, ne kao neke nepromjenjive biti, već kao spleta homeostatskih karakteristika koje se dinamično mijenjaju, ali su ipak statistički dovoljno stabilne da tijekom vremena ostaju prepoznatljive. Te su osobine jedinstvene za ljudsku vrstu i razlikuju se od bilo čega sličnog kod drugih životinja. To što su granice između ljudi i životinja u evolutivnom vremenu nejasne i dinamične, ne znači da čovjek nije fundamentalno različit. 


\section{Ljudska priroda i kultura}

Pluralistički duh vremena u kojem živimo, za koji smatramo da je bez presedana, mogao bi antropološki predstaviti ljudsku prirodu u skladu s narodnom mudrošću »koliko ljudi, toliko ćudi «.

Naravno, dobro osmišljavanje ljudske prirode ne dozvoljava olako prihvaćanje pretpostavke da je svaka individua potpuno poseban slučaj i tu pretpostavku tumači prije kao metaforu za mnoštvo mogućih poistovjećenja. Kao i pri razumijevanju raznovrsnosti kultura, teorija traga za strukturno istim crtama koje zaokružuju identitet pojma, dok (se) razlike trpe. U pozadini ostaju neka pitanja. Primjerice, vodi li isticanje razlika nužno u podjele i postoji li relativno uvijek odvojenost od cjeline (pojma)? ${ }^{18}$ Interesantno je da istočnjačku filozofiju, koja govori o iluziji odvojenosti, prihvaćaju mnogi moderni ljudi u težnji da prevladaju doživljaj odvojenosti u svom životu. ${ }^{19}$

Izražava li ta potreba za prihvaćanjem drevnih mudrosti veoma udaljenih kultura napredak ljudske prirode? Sastoji li se napredak od povezivanja sasvim različitih, gotovo suprotnih pristupa? Je li sposobnost usavršavanja ljudske prirode njena strukturna crta? Zna se da samousavršavanju pomaže vježba i da je navika - 'druga priroda'. Ukazivanje na važnost samodiscipline pripada dugoj tradiciji koja se prenosi od predmodernih vremena. Predsokratovsko odgajanje ljudske prirode služi i danas, bilo u epikurejskom, bilo u stoičkom duhu. Narodno znanje kaže da je »karakter - čovjekova sudbina« $i$ da je svatko »kovač svoje sreće«. Nasljeđe takvih savjeta podsjeća na značaj kultiviranja ljudske prirode jer učinak stihija iz okruženja i sila nesvjesnog čini da priroda (ljudska) podivlja, što nije poželjno ni za individuu, a ni za društvo. To su upute za (samo)odgoj, koji je podloga obrazovanja i koji omogućava ostvarivanje određenih potencijala ljudske prirode: napredak znanstvenog znanja i tehnički razvoj.

11

Ibid.

12

Usp. ibid., str. 10.

13

Ibid., str. 75.

14

Suvremeni kognitivni znanstvenici i neuroznanstvenici ideju 'prazne table' zamjenjuju idejom bilježnice za bojanje kao primjerenijim načinom za opisivanje potencijala ljudske svijesti.

15

Usp. Jesse J. Prinz, Beyond Human Nature: How Culture and Experience Shape the Human Mind, W. W. Norton \& Company, New York, London 2012

16

Riječ je o stoljećima staroj debati koju je formulirao Darwinov rođak Francis Galton. Ta nature vs. nurture debata odnosi se na suprotstavljanje naslijeđenih (genetskih) i stečenih (naučenih) utjecaja na ljudsko ponašanje, osobnost, kognitivne osobine, temperament psihopatologiju.
17

Usp. Kevin Laland, Darwin's Unfinished Symphony: How Culture Made the Human Mind, Princeton University Press, Princeton 2017.

18

Pripadnost mnoštva pojedinačnosti jedinstvenoj cjelini prikazuje zanimljiva metafora Günthera Andersa: »Pojedinačna bića nisu pukotine u našem totalnom sistemu, kao što ni rupe u situ nisu pukotine u situ. Premda se ne sastoje od materije sita, one ipak funkcioniraju kao dijelovi sita, čak kao njegovi najvažniji dijelovi.« - Ginter Anders [Günther Anders], Zastarelost čoveka, prevela Olga Kostrešević, Nolit, Beograd 1985., str. 135.

19

Poznata rečenica Alana Wattsa »Kao što se ocean talasa, univerzum se ljudi «, možda najbolje izražava to jedinstvo. Usp. Alan Watts, The Book: On the Taboo Against Knowing Who You Are, Pantheon Books, New York 1966., str. 13. 
Humanističke discipline svoje poglede o tome što ljudska priroda uopće znači razvijaju u teorijama koje se često suprotstavljaju umjesto da se tretiraju kao komplementarna polazišta za daljnja istraživanja i usavršavanja društva. Antropološka istraživanja ljudske prirode ukazala su na probleme konceptualnih granica i odnosa između individualnog i kolektivnog identiteta, ${ }^{20} \mathrm{a}$ isti problemi postoje pri određivanju drugih koncepata kulture. Nedoumice oko granica i odnosa raznovrsnosti i jedinstvenosti, pojedinačnog i općeg, stvari i pojmova, izraz su prirode ljudskog mišljenja, o čemu svjedoči povijest od skolastike do postmoderne kritike logocentrizma. Zato ne iznenađuje što, promatrana kroz prizmu logike neproturječnosti, procesna priroda stvarnosti ne staje u okvir pojma.

U ovom vremenu raznih obrata i post-istine, koje gubitak spoznajne izvjesnosti nadomještava napretkom tehnike, značenja ovise o interferenciji sila. Dok jedni (ekonomsko-komunikacijski) globalni procesi čine da se kulture miješaju i da međusobno sve više sliče jedna drugoj, drugi (političko-ekonomski) globalni procesi podržavaju razjedinjujuće razlike. Situacija globalne povezanosti ne uređuje se svjesno po principima simetrije i sklada, već se razlikama manipulira i umjesto harmonije mnoštva, monolitno ujednačenje predstavlja se kao nužno. Odigrava se vrenje različitih vrijednosti koje s manjim ili većim intenzitetom utječu na globalne procese i preobražaje identiteta.

Da bi razumjeli i objasnili te procese i moguće utjecali na njihov tijek, teoretičari istražuju i stvaraju koncepte od kojih su vjerojatno najznačajniji oni koji vode usuglašavanju. Tome može biti od koristi drevni pitagorejski princip koji glasi da je priroda u svemu slična samoj sebi - jer to je princip prepoznavanja da simetrija i sklad ${ }^{21}$ postoje u prirodi na svakom planu, dakle, i u svim formama raznovrsnosti. Na tragu uvida da veća stabilnost cjeline počiva na raznolikosti i samim time većoj prilagodljivosti njenih dijelova da je složenost funkcija jednostavnih principa, mogu se usuglašavati različiti koncepti, preobličujući ideju borbe suprotnosti idejom nadopunjavanja.

Kada se neodlučivosti ljudske spoznaje (koja, kao što je rečeno, održava dilemu je li kultura, kao izraz ljudske prirode, dio prirode ili je priroda, kao proizvod ljudskog poimanja, dio kulture) pridruži moderna ideologija napretka, zasnovana na odvajanju prirode i ljudske prirode kao kulture, drama samorazumijevanja ljudske prirode približava se vrhuncu. Komplementarnost prirode i kulture predmoderno vrijeme smješta u okvir prirode, a postmoderno vrijeme prirodu smatra proizvodom kulture. Između toga teče moderno vrijeme - doba modernizacije koje se kreće u smjeru globalizacije.

Počevši s prosvjetiteljstvom, ljudska priroda podijeljena je na fizikalno-biološki plan, koji se odnosi na ono što označava jedinstvo čovječanstva, i na kulturni plan, koji se odnosi na različite tradicije i običaje ljudske vrste. U kontekstu Enciklopedijskog koncepta svijeta, prvenstveno je razvijen koncept čovjeka kao fizičkog bića, dok je etički koncept čovjeka manje ekspliciran. U svakom slučaju, izraženo je zaprepaštenje »'niskošću i užasima', gdje se često 'otkriva taj kralj prirode' «, ali su »prelaženjem preko toga« odbačena »metafizička objašnjenja koja vraćaju na grijeh ili lošu prirodu «. ${ }^{22}$

Prosvjetiteljski humanizam, kako je prikazan u lijepim umjetnostima i filozofiji, kao i u idealu viteštva, zamišljen je tako da služi oblikovanju ljudi. ${ }^{23}$ Pedagogija humanizma trebala je usavršavati ljudsku prirodu - njenu senzualnu stranu - jer ljude kao prirodna bića pokreću pobude za užitkom i drugi sebični interesi. To razmišljanje o potrebi za oblikovanjem ljudske prirode postavlja okvir za dihotomije. U toj društvenoj klimi odvajanja ljudske prirode i kulture ipak se iznosi i drukčije uvjerenje - Rousseauova je 
filozofija o prvobitnoj dobroti ljudske prirode koja se u društvu kvari ukazala na ulogu prirodnih ljudskih prava na slobodu, jednakost i ravnopravnost. Te su vrijednosti u vrijeme svog nastajanja utjecale na transformaciju koncepta društvenog ugovora i na razvijanje građanskih vrlina mimo egoističnih interesa. Ovjekovječene Francuskom revolucijom te su se vrijednosti pokazale tako snažnima da su preživjele urušavanja svih režima koji su na njima bili ideološki konstruirani.

Tako je osvjedočena moć vrijednosti da utječu na oblikovanje koncepta ljudske prirode. Međutim, preuzevši iz antičke definicije čovjeka kao »razumne životinje« vjeru u racionalnost ljudske prirode, humanizam je dao prednost nadmoći razuma nad drugim stranama ljudske prirode. To je izgledalo najracionalnije za oslobađanje od prirodnih uvjetovanosti, odnosno za gospodarenje nad izvanjskom, a donekle i nad unutrašnjom prirodom. Ustvari, koncept usavršavanja bio je izvanjšten, a zatim postavljen kao primarni kontekst modernog shvaćanja napretka jer je

»... povijest ljudi povijest napretka (...), u mjeri u kojoj je zemaljska sreća konačni cilj koji se traži. $\ll^{24}$

To »traženje zemaljske sreće«, u situaciji podijeljenosti ljudske prirode između osjećajnosti i razumnosti i pojednostavljivanja razumnog dijela ljudske prirode na inferiorne elemente, ${ }^{25}$ doprinijelo je preinačavanju koncepta usavršavanja - usmjeren je na »usavršavanje« svijeta i drugih ljudi, odnosno na nastojanje da se oni učine korisnim. Korisnost postaje pokretač modernizacije putem širenja civilizacije i prosvjećenosti. Praktičan činitelj tog povijesnog tijeka bilo je utvrđivanje odgovarajućeg režima društvene hijerarhije oslonjene na vrijednosti kapitalizma koji je poštovanje i čast zamijenio za korist i profit. Na taj način era kapitalizma utvrđuje smisao oblikovanja (ljudske) prirode. Ta era i dalje traje, neprekinuta ni tijekom režima zasnovanih na ideologiji komunizma. ${ }^{26}$

Tako razapeto iznutra, između oprečnih težnji, i izvana, u proturječnom kontekstu modernog pogleda na svijet, samorazumijevanje ljudske prirode zapada u stanje krize. Krizu potiče i obnavlja aporetična struktura mišljenja:

20

Usp. Jelena Đurić, Globalni procesi i preobražaj identiteta, Institut za filozofiju i društvenu teoriju, Albatros Plus, Beograd 2012., str. 263.

21

Usp. Aleksandar Petrović, Analogija $i$ entropija. Filozofija prirode $i$ harmonije Laze Kostića i Koste Stojanovića, Matica srpska, Novi Sad 2005., str. 147. »Simetrija po sebi može biti nepokretna i priopćavati, prije svega, mirovanje, dok je harmonija moguća samo u kretanju i kao kretanje. To je njihova bitna razlika, koja upućuje na objedinjujući pojam ukrštaja (...).«- Ibid., str. 149.

22

Мишел Вовел [Michel Vovelle] (prir.), Човек доба просвећености [Čovek doba prosvećenosti], prevele Vera Pavlović, Mila Samardžić, Clio, Beograd 2006., str. 7.

23

Oblikovanje ljudi potaknuto je tadašnjim enciklopedijski utvrđenim uvjerenjem da je » 'gotovo moguće dati im oblik koji želimo'«. - Ibid., str. 9.
24

Ibid., str. 11.

25

René Guénon kritizira racionalizam koji se »u svim svojim oblicima definira kao vjerovanje u nadmoć razuma, objavljenog kao prava 'dogma', koja podrazumijeva poricanje svega što je nadindividualne kategorije, posebno čiste intelektualne intuicije, što za sobom logično povlači odbacivanje svake prave metafizičke spoznaje«. - Rene Genon [René Guénon], Mračno doba, preveli Nada Šerban, Branko Kukić, Umetničko društvo Gradac, Beograd, Čačak 2008., str. 46.

26

»Što je komunizam? To je ono što ja nazivam totalnim i totalitarnim birokratskim kapitalizmom (...) s ubrizgavanjem kvazireligijskog elementa kojega nema u kapitalizmu (...) i svećenici(ma) te nove vjere koji su bili članovi partije.« - Kornelijus Kastorijadis [Cornelius Castoriadis], Uspon beznačajnosti, preveo Frano Cetinić, Umetničko društvo Gradac, Čačak, Beograd 1999., str. 202. 
antinomije između subjekta i objekta, između unutrašnje potrebe za autonomijom duha i izvanjske uvjetovanosti tjelesnih potreba; proširuju krizu i na odnos među različitim modusima znanja. S jedne strane, razvija se filozofsko razumijevanje ljudskih bića kao odgovornih djelatnika, a s druge strane, moderna znanost promatra ljude iz naturalističke perspektive kao biološku vrstu s određenim svojstvima i težnjama.

Istovremeno, kriza navodi i na usuglašavanje komplementarnih strana ljudske prirode - njene kulturne i biološke strane - kroz usuglašavanje humanističke i znanstvene tradicije. Usuglašavanje je ideal koji potiče samorazumijevanje ljudi kao neovisnih, plodotvornih bića i kao odgovornih sudionika u društvu sposobnih da se razumno i moralno ponašaju. Težnja za dostizanjem tog ideala predstavlja nadahnuće za ljude da usred proturječnosti moderne kulture i civilizacije ne zaborave na značaj oblikovanja ljudske prirode. Otuda potječe želja da se u duhu složenih procesa doživljavanja i rekonstruiranja ideala stvori »nova poetska sinteza $\ll^{27} \mathrm{u}$ cilju oplemenjivanja ljudske prirode povezivanjem u praksi, kao i kroz kulturne i znanstvene prizme, najboljih ljudskih osobina, razumnosti i (su)osjećajnosti, prema svim bićima planeta. Taj ideal usuglašavanja komplementarnosti omogućava obnovu humanizma.

\section{Kritika humanizma}

U kontekstu kritike krize modernosti, humanizam je okrivljen za svođenje svega postojećeg isključivo na »ljudske mjere«. Premda iskustvo pruža razloge za takvo tumačenje, ne treba zaboraviti da to tumačenje koristi sredstva koja kritizira jer svodi pojam ljudske mjere na dio sadržaja tog pojma. Iskustveni razlozi koji opravdavaju kritiku humanizma počivaju na posljedicama epistemološki reduktivnog racionalizma. Te su posljedice važne jer pokazuju čemu vodi mehanicistički pogled na svijet tzv. 'znanstvenog materijalizma'. Kritika redukcionizma koja je svojstvena tom pogledu na svijet upućena je i od strane različitih grana znanosti kojima ne odgovara mehaničko svođenje na najjednostavnije fizičke elemente, s obzirom da to svođenje previđa složenost organski strukturirane stvarnosti. S tim se uspješno nosi i teorija sistema koja podržava novi znanstveni razvoj.

Kritika humanizma također vrši svođenje na reduktivni racionalizam zbog »izbjegavanja svakog principa superiornog poretka i, moglo bi se simbolično reći, odvajanja od neba pod izgovorom osvajanja zemlje ${ }^{28}$ Ta je kritika upućena humanizmu kao »program(u) moderne civilizacije « koji je degradirao ljudsku prirodu, »do najnižeg nivoa i do traženja zadovoljenja potreba svojstvenih samo materijalnoj strani ljudske prirode $\ll .{ }^{29}$

U pogledu redukcionizma očigledno postoji suglasnost različitih stajališta koja su zainteresirana za njegove sasvim različite posljedice. Redukcionizam je omogućio napredak moderne civilizacije, ali po previsokoj cijeni. Mehanicističko provođenje modernizacijskih vrijednosti u ime humanizma očitovalo se kroz prakse eksploatacije, isključivanja i diskriminacije Drugih. To su razlozi nastanka raznih vidova poststrukturalističkog antihumanizma: od feminističkih, do antirasističkih i postkolonijalnih. Antihumanistička kritika ponikla je iz okvira postmodernog diskursa koji je istaknuo eurocentričnu sliku subjekta kao opasan oblik ignoriranja drugih kultura. Ona je usmjerena na humanistički diskurs, odnosno na pretpostavke o ljudskom koje ga strukturiraju, poput poistovjećivanja znanstvene racionalnosti s maskuliniziranim ljudskim. Feminizam je tomu dodao kritiku androcentrične dominacije konceptom ljudskog pretvorene u mjeru svega, ukazujući na to da pseudouniver- 
zalnost te slike ljudskog počiva na zamjeni univerzalno ljudskog parcijalnim ljudskim - bijelim, urbanim, heteroseksualnim, građaninom, muškarcem.

Međutim, u nastojanju da odstrani klasično shvaćanje ljudskog, poststrukturalistička kritika subjekta omogućila je novi apsurd. Teorije historijskog materijalizma i psihoanalize nesvjesnog sačuvale su pojam subjekta koji je nastavio držati moć univerzalnog razuma: unitarnu sposobnost suđenja, hegemonističku upotrebu racionalnosti i ideju da je subjekt znanja zadužen za vlastitu i svjetsku povijest. Rasvjetljavanje odnosa moći i fantazmi na kojima oni počivaju destabiliziralo je dominatorski koncept ljudskog subjekta, ali je time otvoren prolaz za još radikalnije težnje koje su nastale jačim prodorom globalizacije i njenih tehničkih oblika. ${ }^{30}$ Pored toga, ostao je prisutan problem kako istovremeno doći do kritičkog »prepoznavanja vlastitih 'semiotičkih tehnika' proizvodnje značenja i razumne posvećenosti vjerodostojnim pričama o 'stvarnom' svijetu «. ${ }^{31}$

Revizija nekih koncepata poststrukturalističkog mišljenja, koje su u radovima Jacquesa Lacana i Jacquesa Derridaa zasnovane na lingvističkom referentnom okviru i simboličkom posredovanju, vratila je teoretičare na materijalnost tijela i primarnost života (Donna J. Haraway). Posljedica je toga da su pitanja povezana s identitetom zamijenjena naglašavanjem međupovezanosti i mreža odnosa (Bruno Latour). ${ }^{32}$ To je promjena perspektive koja u središte filozofske rasprave o subjektivnosti uključuje globalni objekt svijeta (Michel Serres) ${ }^{33}$ i nastoji redefinirati znanost (Michel Serres, Karen Barad). Povratak na materijalnost tijela, promatranu sa stajališta napredne tehnike kroz ne-personalnu međupovezanost, ne može izbjeći opasnost globalizacije i ugroženih prava kada određuje »posthumanistički obrt« kao preispitivanje etičkih i političkih odnosa moći ljudskih i ne-ljudskih drugosti (Rosi Braidotti). Ontološka orijentacija posthumanizma promatra tehnički napredak kao veliku transformaciju povijesnih uvjeta koji mijenjaju »ljudsko« - unutar i izvan individualno vezanog sebstva. Postantropomorfni pogled posthumanizma samorazumijeva se kao poziv na proširivanje granica kritičkog mišljenja, s težnjom prema tome da otkrije značenja novih odnosa sebstvo - drugi, ma kako to bilo strano za Homo sapiensa. ${ }^{34}$

27

Leticia Worley, The Poiesis of 'Human $\mathrm{Na}$ ture': An Exploration of the Concept of an Ethical Self (disertacija), School of Social Sciences and Psychology, Faculty of Arts, Education and Human Development, Victoria University, Melbourne 2011., str. 3. Dostupno na: http://vuir.vu.edu.au/19374/1/Leticia_Worley.pdf (pristupljeno 27. 2. 2018.). 28

R. Genon [R. Guénon], Mračno doba, str. 27.

29

Ibid.

30

Spektakularni učinci suvremene tehničke transformacije nastaju uslijed konvergencije prethodno različitih grana tehnologije - biotehnologije i genetskog inženjeringa, $s$ jedne strane, i informacijske i komunikacijske tehnologije, s druge. Usp. Anneke Smelik (ur.), The Scientific Imaginary in Visual Culture, V\&R Unipress, Göttingen 2010.
31

Donna J. Haraway, Simians, Cyborgs, and Women: The Reinvention of Nature, Routledge, New York 1991., str. 187.

32

Usp. Bruno Latur [Bruno Latour], Istraživanje o modusima života: jedna antropologija modernih, FMK - Fakultet za medije i komunikacije, Beograd 2015.

33

Usp. Mišel Ser [Michel Serres], »Povratak na Ugovor o prirodi«, u: Jelena Đurić, Srđan Prodanović, Predrag Krstić (ur.), Životna sredina: moralni i politički izazovi, Institut za filozofiju i društvenu teoriju, Službeni glasnik, Beograd 2012., str. 114.

34

Usp. Rozi Brajdoti [Rosi Braidotti], Posthumano, prevela Mirjana Stošić, FMK - Fakultet za medije i komunikacije, Beograd 2016. 


\section{Ekološki diskurs}

Narativ koji upotpunjava postmodernu kritiku logocentrizma kao mehanicistički totalizirajućeg racionalizma, a koji nije antihumanistički orijentiran, nastaje u okviru ekološki orijentirane kritike »monokulture uma ${ }^{35}$ Riječ je o ekološkom diskursu koji kritizira kontekst napretka kao modernizacijskog pogleda na svijet koji uzima profit kao vrhovnu vrijednost. Ostale su vrijednosti iz baštine kulturnih raznovrsnosti, koje nisu u funkciji globalizacije tako shvaćenog napretka, izopćene. Sa stajališta ekološke održivosti, posljedice takvog stanja iziskuju prevrednovanje konteksta napretka shvaćenog kao napretka tehnike, iz čega bi slijedilo odgovarajuće redefiniranje ljudske prirode.

Budući da pojam napretka dobiva svoje određeno značenje i funkciju tek u određenom kontekstu s njemu odgovarajućim vrijednostima, ključan je sadržaj danog konteksta. ${ }^{36}$ Kontekst napretka kao povećanja profita i ekonomske vrijednosti služi kao opravdanje za svu tehničku transformaciju u okruženju po cijenu uništavanja bioraznolikosti. Ovdje je na djelu kontekstualno razilaženje vrijednosti koje se pripisuju konceptima, a 'poboljšanje' u jednom kontekstu znači pogoršanje u drugom. Nešto što iz jedne perspektive predstavlja veću vrijednost, iz druge perspektive znači obezvrjeđenje. Progres tehnologije i transfera sistema osiromašuje ogroman broj ljudi tako što remeti društvene sisteme koji im omogućuju sigurnost i dostojanstvo, a na kraju za sobom ostavlja jalovu zemlju. Zato i na međunarodnom i na lokalnom planu treba pokrenuti zalaganje za zaustavljanje centralizirane kultivacije monokultura jer takva kultivacija uništava staništa s razvijenom bioraznolikošću. ${ }^{37}$

Ekološki i antropološki inspirirana kritika tehnike kontrole društva i eksploatacije profita tiče se modernizacijske perspektive koja ignorira lokalna društva, lišava ih njihova načina života i identiteta. U interakciji s modernizacijom, tradicionalno lokalno znanje prestaje postojati - ono biva nadvladano znanstveno-tehničkim znanjem koje u ime univerzalnosti nameće uniformizaciju svijeta. U tom pogledu ekološki i poststrukturalistički diskursi konvergiraju. Vandana Shiva direktna je u stavu da se moderan sistem znanja predstavlja kao univerzalan u cilju vladavine planetom, iako nema epistemološku univerzalnost, već je to samo jedan partikularan sistem koji pripada jednoj posebnoj kulturi, društvu, klasi i rodu. Drugim riječima, znanstveno-tehničko znanje samo je globalizirana verzija jedne lokalne kulture koja je preuzimanjem moći kapitalizma postala dominatorska. Takav je i njen sistem znanja koje, povezano s moći, generira izrabljivanje i neravnopravnost pod plaštem znanstveno-tehničkog napretka.

Sa stajališta humanih i ekoloških vrijednosti, modernizacijski kontekst napretka zapravo je nazadan jer ne uzima u obzir posljedice koje cjelina života planeta trpi zbog brutalnosti mehanicističkog sistema. To je problem koji povezuje onto-epistemo-etičke činitelje i razlog za preuređivanje epistemološkog plana, odnosno za usklađivanje komplementarnosti između znanstvene racionalnosti i osjećaja ljudi koji ih povezuju s ostalim oblicima života. U tom smislu, određivanje nekog koncepta treba predstavljati sinoptički pregled ${ }^{38}$ koji uključuje svijest o tome da svaki operacionalno definiran koncept sužava polje objašnjivih ljudskih djelatnosti, dok neobjašnjivi dio zahtijeva imaginaciju i odgovarajuće metafore. Tomu doprinosi arhetipski predio psihe koji je izvor imaginacije i posreduje artikulaciju ljudskog iskustva. Ljudi zamišljaju i razumijevaju sebe pripisujući pojmove svojim uvjerenjima, namjerama i željama, pomoću čega učvršćuju svoja stanja. Tako pojmovi koje pripisuju svom ponašanju mogu predstavljati odlučujuće uzročne činitelje u objašnjenju promjena nastalih na osnovi njihova angažiranja. U tom pogledu, samo- 
razumijevanje prirode ljudi, kao razumnih bića, uokviruje njihova »slika o sebi« koja im omogućava orijentaciju prema ciljevima i načinima djelovanja. Bez toga ljudi ne bi znali ni što treba činiti ni zbog čega, a ne bi ni prepoznali svoju ljudskost. ${ }^{39}$ Zato odbacivanje slike o sebi, odnosno koncepta ljudskog (ljudske prirode), ima samoponištavajući učinak i čini od posthumanizma konceptualni rizik za čovječanstvo.

Težeći da se postavi kao »sredstvo genealogije i navigacije« za »ponovno promišljanje « »osnovne referentne jedinice za humano«, posthumanizam preuzima neke heuristički plodne ideje koje su nastale u različitim kontekstima i koristi ih u svoje svrhe. To je slučaj s konceptom kontinuuma priroda-kultura, koji se u kontekstu posthumanizma pretvara u negativni pristup. Takav pristup služi samo za niveliranje razlike između prirode i kulture poništavanjem prirode kao proizvoda kulture. Za posthumanizam koncept kontinuuma predstavlja, dakle, »znanstvenu paradigmu koja se distancira od društveno konstruktivističkog pristupa koji uspostavlja kategoričku razliku između danog (priroda) i konstruiranog (kultura) $\ll^{40}$

$\mathrm{Na}$ taj se način zanemaruje i čak preokreće prvobitni sadržaj pojma kontinuuma kao pogleda na svijet predmodernih kultura, koje u prirodi vide kontinuum iz kojeg izvire ljudsko.

35

Sistem monokulture u agrikulturi poremetio je prirodno okruženje u kojem su tradicionalna društva stoljećima njegovala svoje iskustvo i znanje, na održive načine kultivirala hranu, održavala šume i uzgajala životinje. Usp. Vandana Shiva, Monocultures of the Mind: Perspectives on Biodiversity and Biotechnology, Palgrave Macmillan, London 1993.

\section{6}

Tako u kontekstu individualnog života progres može označavati (samo)poboljšanje $u$ fizičkom, etičkom ili estetskom pogledu, ili pak u psihološkom, emotivnom, duhovnom te u nekom drugom smislu vezanom za individualni razvoj. Kontekst individualnog napretka u istraživanju, poslu, vještini, umjetnosti ili angažiranju u okruženju sadrži vrijednosti povezane sa sociokulturnim planom. Društveni kontekst napretka može se odnositi na poboljšanje odnosa, zajedničkih projekata ili održive organizacije okruženja. Nažalost, ovdje dominira kontekst vezan za tehniku organizacije društva koja ističe interes i kontrolu, a sprječava angažiranje na uspostavljanju održivih odnosa u okruženju.

37

Usp. Vandana Shiva, »Biotechnology Development and Conservation of Biodiversity «, Economic and Political Weekly 26 (1991) 48, str. 2740-2746.

38

Wilfrid S. Sellars u tekstu »Filozofija i znanstvena slika čovjeka« razmatra različite slike čovjeka (i svijeta) - »pojavne« (manifest image) $\mathrm{i} »$ znanstvene (scientific image). Definirana specijaliziranim terminima, znanstvena slika konstruira se oko posebnih konceptualnih modela kojima ne može obuhvatiti pojavnu sliku svijeta. Nasuprot tomu, »pojavna slika čovjeka« predstavlja primarni okvir u kojem čovjek svakodnevno doživljava sebe. Ta je slika dio tzv. »personalističkog znanja koje znanost ne može izvesti (inače bi i slijepa osoba mogla »znati« crveno). Obje slike, pojavna i znanstvena, zajedno upotpunjuju ljudsko znanje (osoba izliječena od sljepila zna više nego što zna samo pomoću znanstvene slike, a poznavanje znanstvene slike proširuje personalističko znanje). U sferi samosvijesti i samospoznaje, personalistička vrsta znanja ima prednost jer integrira osjećaje. Usp. Wilfrid S. Sellars, »Philosophy and the Scientific Image of Man«, u: Robert G. Colodny (ur.), Frontiers of Science and Philosophy, University of Pittsburgh Press, Pittsburgh 1962., str. 35-78.

39

Kao odjek Kantove filozofije, Sellarsova pojavna slika o sebi pruža normu za racionalnu svrhovitost. Pojavna slika svijeta predstavlja osnovni okvir suvremene filozofije (od fenomenologije, egzistencijalizma, kritičke teorije, preko hermeneutike, poststrukturalizma, do analitičke filozofije koja se poziva na zdrav razum i običnu upotrebu pojmova). Svi su pravci suvremene filozofije opći izvještaji o pojavnoj slici čovjeka-u-svijetu koja se zatim smatra za potpuni opis onoga što ljudi i svijet zaista jesu. Usp. ibid.

40

R. Brajdoti [R. Braidotti], Posthumano, str. 31. 
»Ljudski kontinuum može se definirati kao slijed iskustava koji odgovara očekivanjima i težnjama ljudske vrste u okruženju koje je u skladu s onim u kojem su takva očekivanja i težnje stvoreni. (...) Kontinuum pojedinca jest cjelina, a ipak predstavlja dio kontinuuma (...) obitelji, (...) plemena, (...) vrste, (...) svekolikog života. (...) Čak i kontinuum koji obuhvaća sva živa bića očekuje iz iskustva s neorganskim okruženjem izvjestan raspon pogodnih faktora u njemu. U svakom obliku života težnja za razvojem nije slučajna, nego podupire njegove vlastite interese. Težnja za razvojem usmjerena je $\mathrm{k}$ većoj stabilnosti, tj. većoj raznolikosti, složenosti i otuda većoj prilagodljivosti. (...) [D]a bi sistem ostao stabilan, neophodan je otpor promjeni koji nikako nije u sukobu s težnjom k razvoju. (...) Promjena zamjenjuje nešto što je složeno i prilagođeno nečim što je jednostavnije i manje prilagođeno. Posljedica toga je da promjene izazivaju poremećaje ravnoteže (...). Otuda evolucija osigurava stabilnost, a promjena uzrokuje ranjivost. Ta pravila slijede i društvene organizacije. Razvijena kultura (...) može biti bilo koja iz beskrajne raznovrsnosti struktura. Vanjske karakteristike takvih struktura najrazličitije su, a osnovna načela najsličnija su i, u izvjesnom fundamentalnom smislu, teže biti identična. Te bi strukture trebale biti otporne na promjene, pošto su se dugo razvijale, kao i svaki drugi stabilan sistem u prirodi. Iz toga slijedi da će, što manje intelekt smeta instinktu pri stvaranju obrasca ponašanja, struktura biti manje rigidna u svom površinskom sloju (u vezi s pojedinostima u ponašanju, obredima i zahtjevima za udobnošću), a u većoj mjeri nepromjenjiva u samoj jezgri (u stavu prema sebi i prema pravima drugih, osjetljivosti na one signale instinkta koji potpomažu opstanak, zdravlje i zadovoljstvo, uravnoteženost različitih aktivnosti, nagonu za zaštitu vrste, ekonomičnom korištenju biljaka i životinja u okruženju itd.). ${ }^{41}$

U tom smislu, kontinuum priroda-kultura povezan je s arhetipskim predjelom psihe koji pripada ljudskoj prirodi, iako je istisnut iz znanstvene spoznaje modernih ljudi, tako da predstavlja neki vid »personalističke vrste znanja ${ }^{42}$

Preuzimanje ključnih koncepata i pripisivanje njima drugih, posthumanom obratu svojstvenih značenja, mapira de(kon)strukciju ljudskog

»... u biogenetičkom dobu poznatom kao 'antropocen', povijesnom trenutku kada je Čovjek postao geološka sila kadra utjecati na svekoliki život na planetu. Prema tome, posthumana teorija se također može primijeniti kako bi se iznova promislili osnovni principi naše ${ }^{43}$ interakcije s ljudskim i ne-ljudskim akterima na planetarnoj skali.«44

Određivanje granica humanizma drži se uglavnom stajališta antihumanističke kritike, a koncept »posthumane pometnje« služi opravdanju mnoštva nehumanih/nečovječnih događanja. ${ }^{45}$ Time se otvara prostor za posthumano jer se »humano polje« svodi na puku »normativnu konvenciju«, što opravdava isključivanje humanizma.

»(Humana norma) djeluje tako što transponira specifičan način bivanja humanim u generalizirani standard koji postavlja transcendentalne vrijednosti na mjesto čovjeka. (...) Taj standard određen je kao kategorička i kvalitativna razlika u odnosu na seksualizirane, racionalizirane, naturalizirane druge i, također, kao ono što stoji nasuprot tehnološkom artefaktu. Čovjek je povijesni konstrukt koji je postao društvena konvencija 'ljudske prirode'. ${ }^{46}$

Tako promatrana, ljudska priroda tema je koja izaziva nelagodnost. Umjesto modernizacijskom kontekstu napretka, odgovornost se pripisuje ljudskoj prirodi, a oduzima joj se dimenzija ideala, što uzrokuje da njeno odlaganje u muzej zastarjelih koncepata izgleda opravdano. Za posthumani obrat oduzimanje dimenzije ideala predstavlja »gubljenje metafizički privilegiranog položaja « koje je »izmaknulo ontološku sigurnost ljudskoj vrsti«, dok »popularizacija postantropocentrizma « podržava »kolosalnu hibridizaciju s drugim vrstama $\ll .{ }^{47}$

\section{Napredak i ljudska vrsta}

Oduvijek okupirajući umove ljudi, razmišljanje o ljudskoj prirodi tijekom povijesti isticalo je njene različite strane, ali je uvijek uvažavalo samorazu- 
mijevanje općeljudskog identiteta koje pokazuje stanje psihičkog razvoja čovječanstva. Antičko shvaćanje ljudske prirode upućivalo je na samospoznaju; religiozno razumijevanje ljudskog pada pozivalo je na uzdizanje, a prosvjetiteljski pogled na svijet poklonio je vjeru moći razuma da otkriva nužne zakone prirode.

Veliki tehnički progres, koji je time omogućen, nakon stoljeća modernizacije postiže globalno tehničko umrežavanje koje intenzivira promjene i uzdrmava razumijevanje ljudske prirode, odvajajući je od njenih ranijih određenja. To je pokrenuto gubljenjem pouzdanja u mjerila istinitosti i vrijednosti, nakon što su ona bila dovedena u pitanje. Kada su moderno traganje za nužnošću i izvjesnošću, koje je podržavao pozitivistički kult činjenica, zamijenile probabilističke metode, počelo je preispitivanje »istinitosti« uglavljene u konceptualne koordinate znanstvenog materijalizma s hijerarhiziranim pojmovnim dualizmima, polazeći od odnosa subjekta i objekta.

Razvijene u kontekstu pogleda na svijet znanstvenog materijalizma newtonovske mehanike, te konceptualne hijerarhije osiguravale su odnose moći, koji su zauzvrat podržavali vrijednosti znanstveno-tehničkog napretka. Dominacijski odnos prema svijetu, koji je na taj način jačao, oslanjao se na prethodno odvajanje prirode kao izvanjskog prirodnog okruženja od ljudske prirode kao izvora kulture. Zbog toga suprotstavljanje prirode i kulture predstavlja ključno obilježje i problem modernizacije. Međutim, vrednovanje tog suprotstavljanja različito je u suvremenim preispitivanjima:

»Novo promišljanje odnosa između prirode i kulture ističe da je kontinuitet između njih primarniji i dublji od njihovog diskontinuiteta koji je uspostavljen modernizacijom. (...) S jedne strane, taj je pogled u skladu s današnjim osnovama drevnih tradicija, s takozvanim 'predmodernim kulturama' koje su prirodno i ljudsko okruženje shvaćale kao različite aspekte jedinstvene cjeline svijeta. (...) S druge strane, u tijeku je razvijanje (...) stajališta koja kontinuitetu između kulture i prirode pripisuju kulturnu supremaciju smatrajući ju 'prirodnim' opravdanjem za 'kreativnu intervenciju', odnosno za inženjersku i tehnološku manipulaciju sastavnim elementi-

41

Džin Lidlof [Jean Liedloff], Pojam kontinuuma, prevela Vera Nenadov, Clio, Beograd 2001., str. 34-35.

42

Vidi prethodnu bilješku 38, o Wilfridu S. Sellarsu.

43

$\mathrm{Na}$ ovom mjestu nije jasno što zamjenjuje zamjenica »naše«. Kasnije Braidotti kaže da preispituje »tko zapravo čini ovo 'mi' «, kojem »nije dovoljno nepovjerenje u prirodno i zbog kojeg je »potrebno rekonceptualizirati odnos prema tehničkom artefaktu kao nečemu u istoj mjeri intimnom i bliskom, kao što je priroda nekada bila. Tehnički aparat je naše novo 'okruženje'«. - R. Brajdoti [R. Braidotti], Posthumano, str. 115.

44

Ibid., str. 34. Zapravo, Braidotti preuzima ideju koju iznosi Dipesh Chakrabarty u svom radu »The Climate of History: Four Theses «, nevoljko ga spominjući tek nakon šezdeset stranica, kada kaže da se isti zaključci koje njih dvoje imaju odnose na problem »promjena razumijevanja ljudskog utjecaja, od tek biološ- kih do danas geoloških faktora«. Chakrabarty, međutim, ne prati postantropocentrični način mišljenja pa Braidotti kaže da protežiranje kulture »tehno-teratološke imaginerije društva« služi rasplamsavanju »postantropocentrizma« koji odgovara na »potrebu za preobražajem subjekta«. Preobražaj subjekta ne mora se ipak odvijati u posthumanom smjeru, kao što pokazuju filozofije Michela Serresa i Bruna Latoura, koji geocentrični obrat subjektivnosti radije vide u okviru ekološke problematike. U duhu »novog materijalizma«, Braidotti »osnovu posthumanosti« opisuje hipotezom o »vitalnoj samoorganizirajućoj (autopoietičkoj) strukturi i moći žive materije« koja ima »nenaturalističku strukturu«. - Ibid., str. 31.

45

Usp. ibid., str. 38.

46

Ibid., str. 56.

47

Ibid. 
ma prirode. Na taj se način podržava znanstveno-tehnološki razvoj u funkciji kontrole svijeta i ostvarivanja profita bez obzira na ekološku i ljudsku (ne)održivost. $\ll^{48}$

Ne treba zaboraviti da odvajanje ljudskog od prirodnog počiva i na modernom razumijevanju onoga što je differentia specifica ljudske vrste, koju odlikuje sposobnost stvaranja artefakata kao materijalizacije kulture kao akumuliranog znanja i čije prenošenje predstavlja kontekst napretka. To se odnosi na stvaranje kulture koja uključuje i tehniku, kao vještinu svladavanja okruženja, koja je tisućama godina posredovala ljudski odnos s prirodom i utjecala na njene promjene. Međutim, od industrijske revolucije intenzivira se moć tehničkog posredovanja, osobito razvojem novih tehnika i teorija koje omogućuju i osvjetljavanje modernizacijskih kriza. U sistematičnom prikazu uzroka i posljedica različitih modernih kriza, Charles Eisenstein uspijeva održati optimističan pogled na ljudsku prirodu i vjeru u mogući uspon čovječanstva unatoč tome što iako sagledava širenje negativnih tekovina ljudske kulture, nepravde i nasilja, zbog kojih svladavanje okruženja vodi njegovu uništavanju, a nasilje i destrukcija rezultiraju »konvergencijom kriza «. ${ }^{49}$

Antropološki pesimizam koji ističe negativne strane ljudske prirode, uz tezu da je krivica za destrukciju prirode ljudskog podrijetla, izvor je kritike humanizma i antropocentrizma. Taj negativni pogled nastoji, preko 'postantropocentrizma', kroz umjetnost sublimirati uništavanje prirodnog okruženja koje prihvaća kao neizbježnu cijenu civilizacijskih znanstveno-tehničkih dostignuća, a toksične učinke tehnike smatra neodvojivim od povlastica koje ona pruža. Međutim, pripisivanje krivice za destrukciju prirode 'ljudskoj prirodi' ne samo što time nije opravdano nego je ono i štetno jer sprječava koncipiranje konteksta napretka kao ljudskog stvaranja boljeg svijeta.

Radikalnije od toga misli Eisenstein kada tvrdi da zajednički korijen problema i kriza civilizacije nije ljudska priroda, već upravo njeno negiranje. Ono, naime, leži u pogrešnom poimanju sebe i svijeta, u definiranju sebe kao izoliranih subjekata, odvojenih od drugih i svijeta. Mogućnost prevladavanja negativnih utjecaja tehnike i transponiranja individualnog iskustva vidi $u$ povezivanju sa svijetom (bez pritisaka modernog načina života) i podizanju tog stanja povezanosti na razinu kolektiva, što treba omogućiti osmišljavanje preuređenja svijeta. Ljudi mogu uživati u suradnji, dopuštajući zajedničkim ciljevima da ih ponesu, i tako prestati trpjeti nesretno ljudsko stanje, odnosno nemoć pred nepravdom i nasiljem koji obavijaju planet, dok stanje povezanosti sa svime pripisuju nekom idealnom svijetu.

Antropološki optimizam, koji Eisenstein širi, izražava se u vjeri da je ljudska priroda dobra i da može otkriti i prevladati ono što ljude sprječava da se zauzmu za bolji svijet za koji srcem znaju da je moguć. Velika je prepreka pogled na svijet kojeg se teško osloboditi. To je opći pogled moderne civilizacije koji je utkan u ljudsku tehniku i kulturu, a preko njih utisnut u individue. Zbog toga mnogi misle da je negativni pogled na svijet (i ljudsku prirodu) neizbježan jer idemo ka kolapsu svega poznatog, a prema shvaćanju Eisensteina, upravo tom kolapsu vodi konvergencija kriza.

Sve u svemu, nastupilo je doba Antropocena, koje je označeno kao prelazak ljudske vrste iz statusa bioloških činitelja planeta u status geološke sile Chakrabartyjevo ${ }^{50}$ razmišljanje o tome ide u smjeru obnove humanizma, tako što upućuje ljude na to da preuzmu odgovornost za moć koja ima dimenziju sile prirode. Tu odgovornost treba udružiti s potrebom, koja je također inherentna ljudskoj prirodi, za ponovnim povezivanjem s prirodom, što zahtijeva preobražaj sistema (mišljenja, politike, ekonomije, obrazovanja, organizacije društva i uopće svih oblika kulture i tehnike) koji odvaja ljudsko od prirode. 
Ponovno povezivanje s prirodom zahtijeva rekonceptualizaciju ljudske prirode i u tom smislu predstavlja obnovu humanizma. To razmišljanje suprotstavlja se posthumanizmu koji negira i ljudsko i prirodu, koju određuje kao ljudski »kulturni konstrukt« lišavajući ga supstancijalnosti, ali i odgovornosti za moć da posredstvom kulture i tehnike odlučujuće utječe na sistem. Međutim, zalaganje za ukidanje ljudskog i konceptualni kraj prirode ${ }^{51}$ nije rješenje za ugrožavanje života planeta. Chakrabartyjev neohumanizam, na koji upozorava Braidotti, polazi od opasnosti globalizacije napretka modernizacije koji na opasan način teži ukidanju podjele između ljudske i prirodne povijesti. Globalna dimenzija moći (nekih pripadnika ljudske vrste koja se očituje posredstvom tehničkog upravljanja globalnom civilizacijom i kulturom) obvezuje ljude na preispitivanje svega što može utjecati na taj kolaps. To se odnosi, dakle, i na preispitivanje koncepta ljudske prirode, umjesto da se ljudskoj prirodi kao takvoj pripisuje sklonost zloupotrebi moći.

U doba Antropocena, kada je tehnika proglašena za »drugu prirodu«, dolazi i do osvještavanja situacije u kojoj tehnika mijenja prirodu izvana, a kultura iznutra, u sferi uma i duha, mijenja ljudsku prirodu. Problem je, kako kaže Eisenstein, što dominacija prirodom pomoću tehnike i ljudskom prirodom pomoću kulture odvaja ljudsku vrstu od ostatka života. Ako se to naziva napredak, onda se previđa kriza koju on stvara pogledom na svijet koji odvajanje ljudi od prirode smatra upravo onim što ljude određuje kao ljude. U tome je paradoksalnost ljudske situacije u doba globalizacije/modernizacije koje uvećava odvojenost i krizu. Eisenstein govori o konvergenciji kriza koje se u svim sferama tiču odvajanja: religiozni govore o odvajanju od Boga, ekolozi o uništavanju prirode, društveni aktivisti o raspadu zajednice ili o međusobnom odvajanju ljudi, a iz psihološkog se ugla odvajanje odnosi na one dijelove nas samih koje potiskujemo i koji prave probleme. ${ }^{52}$

Razmišljanje o ljudskoj prirodi na osnovi individue uključuje ono na što su stoljećima ukazivali mudraci koji su govorili o iluziji identiteta koja izaziva patnju i krizu, a iz koje se izlazi otvaranjem viših nivoa svijesti. Uslijed povezanosti svega i na osnovi duhovne dimenzije globalne krize, koja je imanentna materijalnoj, pomak u samorazumijevanju individue povezuje se s pomakom na kolektivnom planu, kao što postoji i obrnuta veza. Odvajanje ljudskog

48

Jelena Đurić, »Permakultura kao nova politička kultura«, Kultura: časopis za teoriju $i$ sociologiju kulture i kulturnu politiku (2015) 149, str. 56-71, str. 59-60.

49

Usp. Charles Eisenstein, The Ascent of Humanity: Civilization and the Human Sense of Self, North Atlantic Books, Berkeley 2013. Dostupno na: http://ascentofhumanity.com (pristupljeno 10. 12.2018.)

50

Usp. Dipesh Chakrabarty, »The Climate of History: Four Theses«, Critical Inquiry 35 (2009) 2, str. 197-222, doi: https://doi. org/10.1086/596640.

51

»Nakon objavljivanja knjige o kraju prirode [Bill McKibben, The End of Nature, Random House, New York 1989.], novo ime za staru prirodu postalo je okruženje (environment) U središte pažnje došle su globalne promjene klime koje su opisane kao 'nenamjeravane' posljedice manipulacije atmosferom. Time je označeno iščezavanje nama poznate prirode. (...) [Z]a razliku od prethodnih generacija koje su nastanjivale prirodni svijet, ostavljajući ga nakon svog djelovanja netaknutim, mi i naša djeca možda ćemo živjeti u svijetu koji će pod utjecajem ljudskih aktivnosti imati potpuno izmijenjenu biosferu planeta. Takav svijet više neće razlikovati prirodu od ljudskih tehnoloških intervencija.«-J. Đurić, »Permakultura kao nova politička kultura«, str. 58 .

52

Usp. C. Eisenstein, The Ascent of Humanity. 
od prirode utječe na otuđenja pojedinačnih ljudi od prirode, života, duha, od sebe, a ekološki problemi pokazatelj su toga stanja ljudske prirode i vrste.

»[M]oderni čovjek ne posjeduje sposobnost da vlada tehničkim sredstvima koja je stvorio, a koja, što su savršenija, to mu više izmiču iz ruku, pretvarajući se od instrumenta za zadovoljavanje individualnih i društvenih potreba, u sredstva za destrukciju života, bilo njihovom upotrebom u militantne svrhe i stvaranje sve moćnije vojne industrije, bilo uništavanjem i zagađivanjem prirode. $\ll^{53}$

Uvjetovano i ovisno, odvojeno od prirode i drugih ljudi, ljudsko biće podložno je iskušenju da sve iskorištava za sebe. Iako iluzoran po svjedočenjima prosvijetljenih, »privid odvojenosti « tako je moćan da proizvodi krizu u svim aspektima života. Eisenstein je pokazao da je čak i kapitalistički ekonomski sistem simptom, a ne uzrok te odvojenosti. Uzrok je ljudsko sebstvo koje je oblikovano modernim pogledom na svijet (cogitom Descartesa, »ekonomskim čovjekom ${ }^{54}$ Adama Smitha, Darwinovim individualnim fenotipom koji se natječe za resurse, »kožom omotanim egom« kojeg opisuje Watts). Preko toga, izopačuje se i ideja napretka kao ljudskog usavršavanja i konstruktivni potencijal tehnike kao sredstva da se poboljša svijet. U kontekstu opće odvojenosti, svaki tehnički progres, koji bi trebao služiti oslobađanju od naših prirodnih ograničenja, još nas više odvaja i od prirode i od naše vlastite ljudske prirode.

Redefiniranje ljudske prirode, uzajamnih odnosa i odnosa prema prirodi iziskuje preispitivanje pogleda na svijet klasične znanstvene kozmologije, koja stvara doživljaj izoliranosti kod ljudi koji kozmos promatraju kao stroj. ${ }^{55}$ Početkom 20. stoljeća taj je pogled na svijet Max Weber označio kao »raščaravnje « da bi ukazao na to da je mehanički kozmički poredak u kojem se utemeljuje ljudsko postojanje, smisao i svrha, lišen duha, simbolike i izražaja. Raščaravanje nije suočavanje sa stvarnošću, već s krizom koja pritišće čovječanstvo. Vrijeme je da se pronađe izlaz, da se izbori za ishod preobražaja. To pretpostavlja najprije borbu sa sumnjom da su ljudi dio prirode i da je odvojenost iluzija, što nije lako jer izgleda kako ta »iluzija« proizvodi silu koja transformira planet. Također, treba odagnati strah da ljudska djela i misli nisu prirodni jer je od njih stvoreni svijet tehnike neautentičan. Naposljetku, treba prevladati strepnju koja nastaje uslijed razapetosti između 'jest' i 'treba' i ostalih aporija uma. Novi pogled na ljudsku prirodu ima važne filozofske posljedice zato što s njim znamo da ljudsko biće, usprkos izvanjskim i unutrašnjim utjecajima (biološkim, genetskim, psihološkim, kulturnim, tehničkim i drugim) ima volju za smislom. Zahvaljujući smislu, koji vidi za sebe i za cijelu sredinu, čovjek može prevladavati ograničenja, svoja i situacijska, i imati autentičan život. Je li za ljudsku prirodu moguće zamisliti neki povoljniji kontekst napretka? 


\title{
Jelena Đurić
}

\section{Human Nature and the Context of Progress}

\begin{abstract}
I intend to show in what way the meaning of the concept of human nature emerges from the worldview that, taken within the context of modernization, leads to the devaluation of the meaning of human. Hence the need to re-conceptualize human nature emerges in such a way that the concept of human nature is necessary intertwined with the global processes and onto-epistemo-ethical aspects of the general worldview that designate the (self)understanding of contemporary culture. The aporetic structure of thinking poses a barrier to this goal. Its context of modern progress is based on the separation of nature and culture. The separation establishes an (im)possibility of answering the question whether the culture, as an expression of human nature, is a part of nature or the nature is, as a product of human comprehension, a part of culture. Instead of the posthuman strive to resolve this dilemma by abolishing the concept of human, which resolves neither ecological nor other types of crisis, the concept of human nature needs to be redefined.
\end{abstract}

\section{Keywords}

human nature, nature, culture, progress, anthropocene, posthumanism

53

Zagorka Golubović, Pouke i dileme minulog veka, Izdavačko poduzeće Filip Višnjić, Beograd 2006., str. 35 .

54

Homo oeconomicus označava čovjeka kao konzistentno racionalno biće ograničeno osobnim interesima tako da ima najbolji odnos prema osobnim ciljevima i interesima. 55

Richard Tarnas fantastično je dočarao različite epistemološke poglede na svijet kao moguće pristupe kozmologiji. Zamišljajući da Univerzum (žena) nije raščaran, mehanički kozmos moderne kozmologije, »nego duboko oduhovljeni, istančano tajanstveni kozmos velike duhovne ljepote i kreativne inteligencije «, on joj postavlja pitanje: »Kome bi od njih odala svoje najdublje tajne? Kojem bi pogledu otkrila svoju najautentičniju prirodu?« Onomu koji joj pristupa kao da joj bitno nedostaje inteligencija i smisao, da nema unutrašnje dimenzije o kojoj bi govorila, da je bez duhovne sposobnosti ili vrijednosti i koji bi je vidio kao inferiornu u odnosu na njega; koji se prema njoj odnosi kao da njeno postojanje ima vrijednost samo u mjeri u kojoj on može razviti i iskoristiti njene resurse da bi zadovoljio svoje potrebe; i čija je motivacija da je upozna u krajnjoj liniji vođena željom da uveća svoju intelektualnu moć, predvidivost i djelotvornu kontrolu nad njom radi vlastite samoočaranosti? Ili bi se otvorila najdublje onom proscu koji je, u najmanju ruku, vidi kao inteligentno, plemenito i vrijedno biće, obdareno umom i dušom, moralnim očekivanjima i smislom, duhovnom dubinom i tajnom, kao i on? Taj je prosac hoće upoznati, ne da bi je bolje iskoristio, nego da bi se s njom sjedinio i na taj način doprinio nečem novom, kreativnoj sintezi koja nastaje iz obostranih dubina. On želi osloboditi ono što je bilo skriveno uslijed odvojenosti znalca i znanog. Krajnji cilj njegova znanja nije uvećavanje moći, predvidivosti i kontrole, već bogatije i snažnije sudioništvo u su-stvaralačkom odvijanju novih stvarnosti. On traži intelektualno ispunjenje povezano s maštovitom vizijom, moralnim preobražajem, suosjećajnim razumijevanjem, estetskim užitkom. Njegov čin spoznavanja zapravo je čin združene ljubavi i mudrosti, čuđenja, kao i brižnosti za otvaranje prema procesu uzajamnog otkrivanja. »Kojem bi proscu Univerzum prije otkrio svoje najdublje istine? «- Richard Tarnas, »Two Suitors: A Parable«, International Journal of Transpersonal Studies 23 (2004) 1, str. 129-131, str. 129, doi: https:// doi.org/10.24972/ijts.2004.23.1.129. 